\title{
Anomalous Origin of the Right Coronary Artery from the Mid-Left Anterior Descending Artery: A Rare Coronary Anomaly
}

\author{
Mário Barbosa Guedes Nunes, Samir Ibrahim Duarte, Rafael Alexandre Meneguz Moreno, \\ Antonio de Castro Filho, Edgar Stroppa Lamas, Sérgio Navarro Braga
}

\section{ABSTRACT}

A single coronary artery is a rare anomaly that may be associated with myocardial ischemia and sudden death. We present a case of a young woman with atypical angina whose coronary angiography revealed a right coronary artery originating from the mid left anterior descending artery, a variant of the single coronary artery.

DESCRIPTORS: Coronary vessel anomalies. Coronary angiography. Coronary vessel anomalies/diagnosis. Diagnostic imaging/methods.

C ongenital coronary artery anomalies are found in 0.3 to $5.6 \%$ of patients undergoing coronary angiography and in $0.3 \%$ of autopsies. ${ }^{1}$ The presence of a single coronary artery, characterized as a coronary artery with its origin in one of the sinuses of Valsalva and that irrigates the entire heart, is a rare anomaly, representing $3.31 \%$ of all coronary congenital anomalies, and can be associated with myocardial ischemia and sudden death. This report details the case of a female patient whose right coronary artery had its origin from the left anterior descending artery, a variant of single coronary artery (type LII of Lipton's classification). ${ }^{2}$

\section{RESUMO}

\section{Artéria Coronária Direita Originada da Artéria Descendente Anterior: Uma Rara Anomalia Coronariana}

A artéria coronária única é anomalia rara, que pode estar associada à isquemia miocárdica e morte súbita. Apresentamos o caso de uma mulher jovem, com quadro de angina atípica, cujo cateterismo revelou artéria coronária direita que se originava do terço médio da artéria descendente anterior, uma variante da artéria coronária única.

DESCRITORES: Anomalias dos vasos coronários. Angiografia coronária. Anomalias dos vasos coronários/diagnóstico. Diagnóstico por imagem/métodos.

\section{CASE REPORT}

Female patient, 42 years old, with a history of a stabbing retrosternal chest pain, not related to physical effort, which had begun 2 months previously. The patient had a history of hypertension, dyslipidemia, and obesity, and a family history of premature coronary disease. Physical examination and electrocardiogram (ECG) at rest were normal. The stress test was positive for ischemia by electrocardiographic criteria (ST-segment depression of $1 \mathrm{~mm}$ in the inferior leads and in MC5), with indication for coronary angiography. 
A coronary angiography, performed via femoral access (6 F sheath and catheters), showed a single coronary ostium originating in the left coronary sinus, followed by the common trunk, with a normal-looking path, branching off into the left anterior descending and left circumflex arteries, with left dominance. In the middle third of the left anterior descending artery, a small-caliber branch directed towards the right was observed, with its probable path coursing anterior to the pulmonary artery and to the right ventricle outflow, and identified as an anomalous origin of the right coronary artery. The aortography showed an absence of the right coronary artery from the right coronary sinus. The coronary arteries were free of obstructive lesions and a left ventriculography revealed normal contractile function (Figure 1A to 1F). The arterial sheath was removed immediately after the procedure, and the patient remained at rest for three hours and was discharged uneventfully. Magnetic resonance imaging of the coronary arteries was requested to confirm the path of the anomalous vessel.

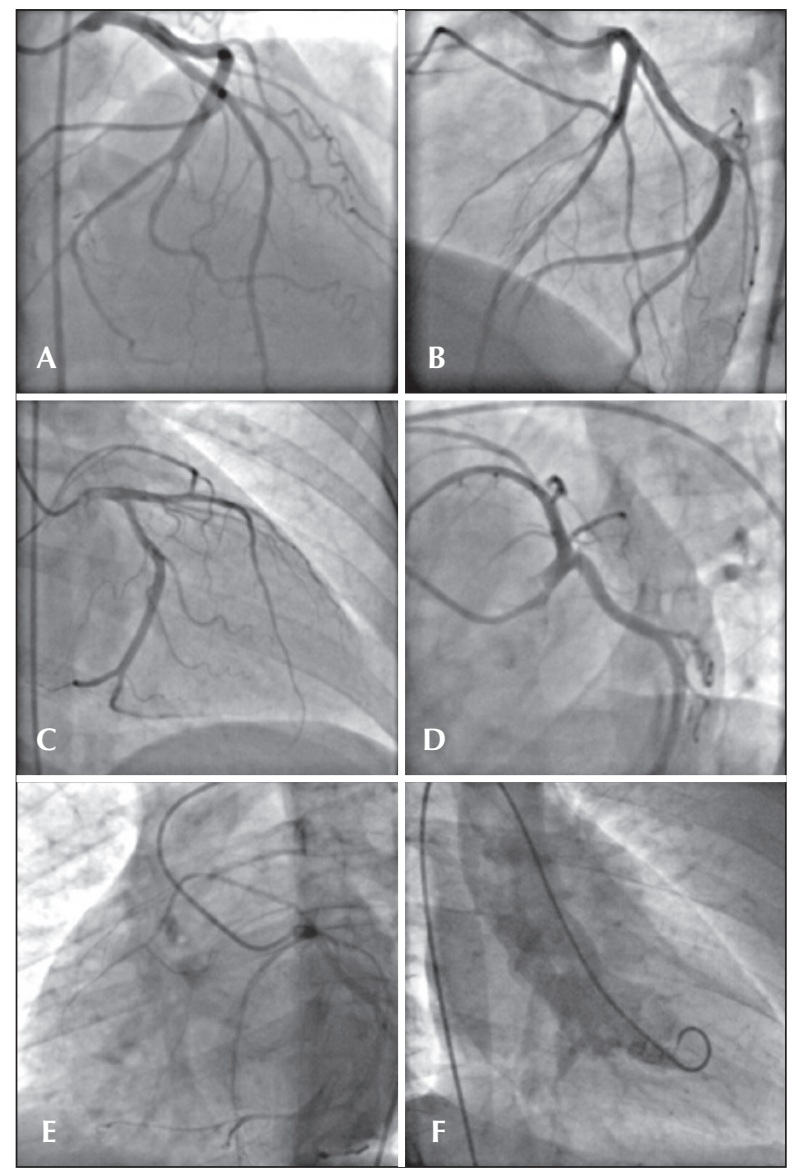

Figure 1 - Right coronary artery, originating from left anterior descending artery after the emergence of the first diagonal branch, coursing to the right, anterior to the pulmonary artery and to right ventricle outflow. (A) Right oblique incidence with cranial angulation. (B) Left oblique incidence with cranial angulation. (C) Right oblique incidence with caudal angulation. ( $D$ and $E$ ) Left oblique incidence with caudal angulation. (F) Left ventriculography.

\section{DISCUSSION}

Cases of right coronary artery with its origin from left anterior descending artery are rare in medical literature. Less than 30 cases have been listed in a recent review, of which 11 had originated in the mid third of the left anterior descending artery, and none of them coursed between the aorta and pulmonary trunk. ${ }^{3}$

According to the classification of Lipton, cases of anomalous right coronary artery originating from left anterior descending artery correspond to a type LII coronary anomaly. However, when the right coronary artery emerges from the middle third of the left anterior descending artery, it is not possible to assign a precise classification, since group II abnormalities include only those originating from a proximal segment of the right or left coronary artery. ${ }^{4}$

The main reason for identifying and classifying coronary abnormalities is generally to determine their susceptibility to the development of myocardial ischemia and sudden death. Some of these anomalies may produce a persistent (anomalous left coronary artery originating from pulmonary trunk, coronary ostial atresia, or critical stenosis due to the angulation of the vessel and to an intramural course) or dynamic (anomalous origin of a coronary artery from the contralateral coronary sinus, coronary fistulas, or myocardial bridges) ischemia. ${ }^{1-3}$

The origin and course of anomalous coronary arteries are the major predictors of risk for fatal events. When the anomalous coronary artery is coursing between the aorta and the pulmonary artery, this picture is associated with myocardial ischemia and sudden death, due to the susceptibility to extrinsic compression by great vessels. ${ }^{1-8}$ In these situations, and as soon as the ischemia has been demonstrated, coronary artery bypass graft surgery (CABG) is recommended (class I, level of evidence B). ${ }^{9}$ Other possible mechanisms associated with transient ischemia in territories irrigated by anomalous coronary arteries include a very closed exit angle, slit-like ostia, an intramural course, or coronary spasm. ${ }^{4,6}$

Usually, the ectopic origin of the right coronary artery from the left anterior descending artery, a single coronary artery subgroup, is a benign event and does not affect coronary perfusion. ${ }^{4}$ However, a non-invasive imaging method, such as computed tomography or magnetic resonance imaging of the coronary arteries, should be performed to confirm the course of the anomalous vessel (Figure 2). The strategy for management of these patients varies according to the clinical presentation, anatomical details, and additional findings.

\section{CONFLICTS OF INTEREST}

The authors declare no conflicts of interest.

\section{FUNDING SOURCES}

None. 


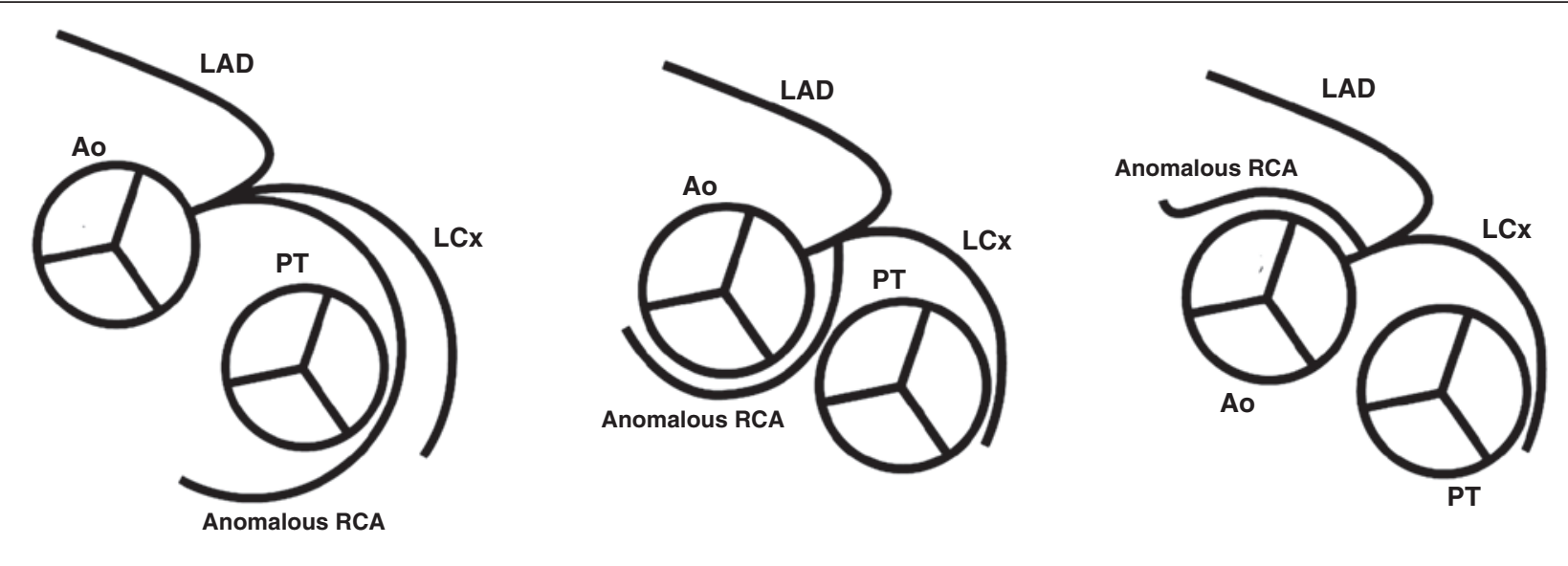

Figure 2 - Schematic representation of the routes of an anomalous right coronary artery. ${ }^{4}$ On the left, an anomalous right coronary artery which anteriorly originates from the left anterior descending artery, anteriorly targeting the pulmonary trunk, before reaching the right atrioventricular groove. At the center, an anomalous right coronary artery, with a route between aorta and pulmonary trunk. On the right, an anomalous right coronary artery, coursing subsequently to the aorta. Ao: aorta; RCA: right coronary artery; LCx: left circumflex coronary artery; LAD: left anterior descending; PT: pulmonary trunk.

\section{REFERENCES}

1. Angelini P, Velasco JA, Flamm S. Coronary anomalies: incidence, pathophysiology, and clinical relevance. Circulation. 2002;105(20):2449-54.

2. Antunes N, Meireles A, Gomes C, Vieira M, Anjo D, Santos $M$, et al. Origem anômala da coronária direita e enfarte agudo do miocárdio: causa ou coincidência? Rev Port Cardiol. 2012;31(7-8):509-12.

3. Yurtdas M, Güllen O. Anomalous origin of the right coronary artery from the left anterior descending artery: review of the literature. Cardiol J. 2012;19(2):122-9.

4. Yamanaka O, Hobbs RE. Coronary artery anomalies in 126.595 patients undergoing coronary angiography. Cathet Cardiovasc Diagn. 1990;21(1):28-40.

5. Veras FHAPV, Victor EG, Saraiva LCR, Lopes MMU. Origem anômala das artérias coronárias. Rev Bras Cardiol Invasiva. 2007;15(3):285-92.
6. Angelini P. Coronary artery anomalies: an entity in search of identity. Circulation. 2007;115(10):1296-305.

7. Jo Y, Uranaka Y, Iwaki H, Matsumoto J, Koura T, Negishi K, et al. Sudden cardiac arrest associated with anomalous origin of the right coronary artery from the left main coronary artery. Tex Heart Inst J. 2011;38(5):539-43.

8. Warnes CA, Williams RG, Bashore TM, Child J, Connolly H, Dearani J, et al. ACC/AHA 2008 guidelines for the management of adults with congenital heart disease: a report of the American College of Cardiology/American Heart Association Task Force on Practice Guidelines. Am Coll Cardiol. 2008;52(23):e143-263.

9. Erdogan O, Buyuklu M, Aktoz M. Anomalous origin of the right coronary artery from the left anterior descending artery: case report and review of the literature. Int J Cardiol. 2008;127(2):280-3 